\title{
Design of Tall Cable-Supported Windbreak Panels
}

\author{
Chrysanthos Maraveas ${ }^{1,2}$ \\ ${ }^{1}$ Department of Civil Engineering, University of Patras, Rio, Greece \\ ${ }^{2}$ C. Maraveas \& Associates P.C., Consulting Engineers, Athens, Greece \\ Email: c.maraveas@maraveas.gr
}

How to cite this paper: Maraveas, C. (2019) Design of Tall Cable-Supported Windbreak Panels. Open Journal of Civil Engineering, 9, 106-122.

https://doi.org/10.4236/ojce.2019.92008

Received: April 4, 2019

Accepted: June 1, 2019

Published: June 4, 2019

Copyright (c) 2019 by author(s) and Scientific Research Publishing Inc. This work is licensed under the Creative Commons Attribution International License (CC BY 4.0).

http://creativecommons.org/licenses/by/4.0/

\begin{abstract}
The design and construction of tall and slender steel structures is always challenging. This paper discusses several design aspects (structural information, analysis methods, applied loads, cost optimisation) and a case study regarding the design and construction of 10-m-tall windbreak panels for a Greek electricity producer. The purpose of the panels is to reduce wind turbulence and improve the performance of the electricity producer's air-cooled condenser. In this case, the main wind load acts in the longitudinal direction, with friction inducing only a small amount of wind load in the transverse direction. The steel columns are constructed from 10-m-tall hot-rolled IPE 270 (S235) cross-sections, and are supported by cables in the longitudinal direction and bracing systems in the transverse direction. Concrete anchorages and concrete footings are used for the cables and steel columns, respectively. System optimisation is investigated in terms of the steel weight, cable length, and overall cost, and practical issues are explained regarding technical decisions. Furthermore, the construction details, construction methods, and cost estimation are discussed.
\end{abstract}

\section{Keywords}

Windbreak Panels, Wind, Cables, Steel Structures, Tall, Slender

\section{Introduction}

Windbreak panels have many different purposes. They can be used to improve living conditions (Figure 1(a)), reduce noise (Figure 1(b)), protect agricultural production (Figure $1(\mathrm{c})$ ), protect thin manufactured materials in mining and industry (Figure 1(d) and Figure 1(e)) [1], and generally improve production, and environmental conditions [2] [3]. Windbreaks are typically man-made 


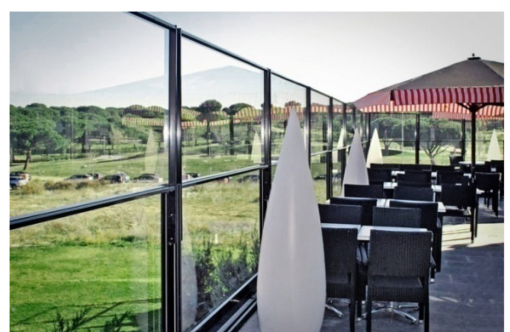

(a)

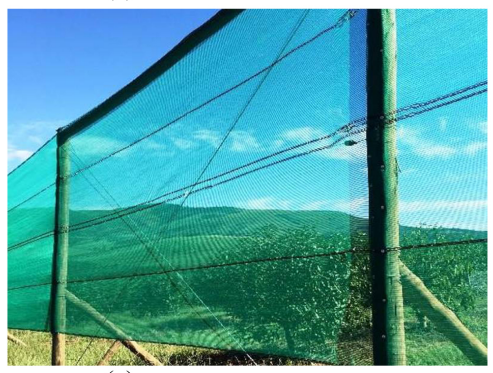

(c)

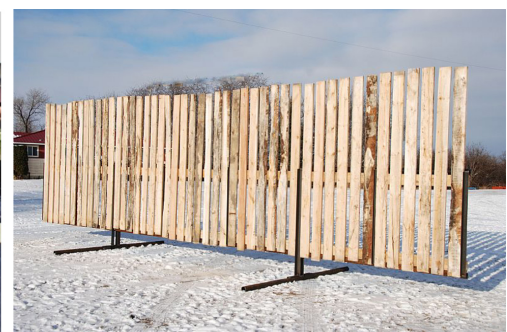

(b)

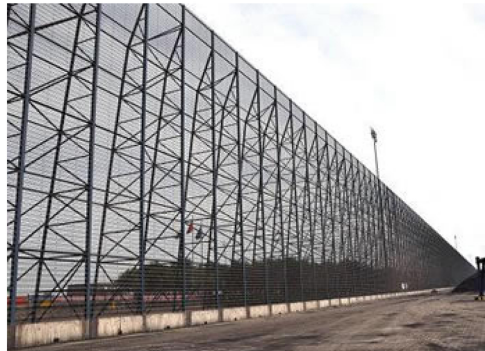

(d)

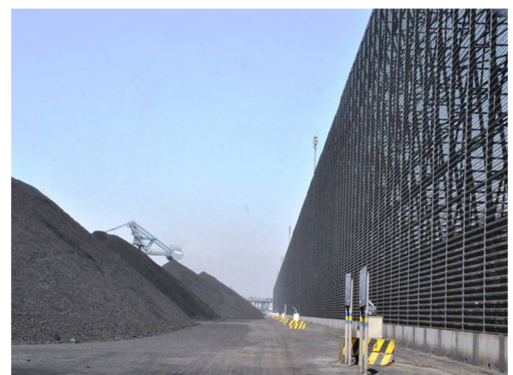

(e)

Figure 1. Windbreaks for (a) improving living conditions, (b) noise control, (c) protecting agricultural production, and (d), (e) protecting mining and industrial production.

structures, but trees can also be used for the same purpose [4].

The way in which a windbreak affects the wind flow is complex and depends on several parameters: 1) the land geometry, 2) the height of the windbreak, and 3) the materials used. The latter can be porous to allow the wind to pass partially through the windbreak, thus reducing the wind force. Figure 2(a) presents a schematic of wind flow near a windbreak, and Figure 2(b) shows how porous windbreak materials affect the performance of the windbreak. Useful information regarding the effects of porosity on the behaviour of windbreak panels can be found in [5] [6] [7].

Tall windbreaks require huge foundations to withstand the overturning moments caused by the wind load, while the structural part of the windbreak requires both high moment and shear capacities. Another approach is to use a lateral system to support the windbreak structure and reduce the applied loads and applied moments, thereby avoiding the structural system having to act as a cantilever. Tall and slender structures that are affected by wind loads (e.g. chimneys) are usually supported laterally by cables, and this approach can also be adopted for tall windbreaks. 


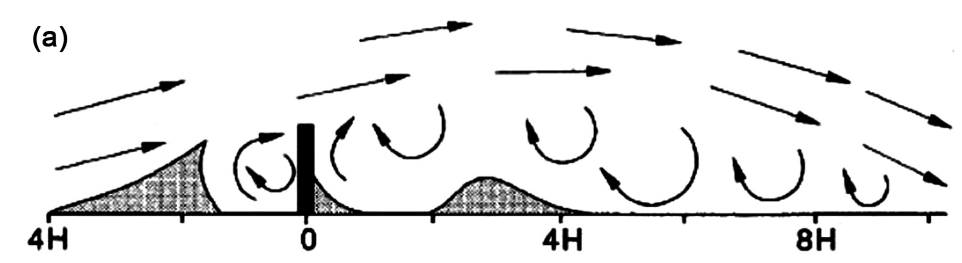

Solid Fence

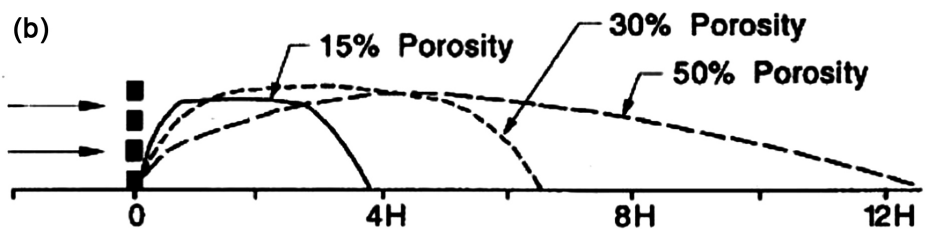

Porous Fence

Distance From Fence $(\boldsymbol{H}=$ fence height)

Figure 2. (a) Wind flow affected by a windbreak. (b) Effect of porosity percentage on wind flow.

The energy production industries are among those that use airflow to cool water. For their purposes, the airflow must be constant and directed mechanically; unstable wind flows can reduce the effectiveness of the cooling system, causing serious production issues. Such problems can be reduced by using windbreaks [8]. This paper discusses some basic issues related to the design of a tall $(10 \mathrm{~m})$ windbreak panel structure for a cooling system. The windbreak is supported laterally by cables that run in the same direction as the wind (referred to herein as the longitudinal direction).

\section{Wind Action}

As expected, the wind load is the dominant force acting on windbreak panels. The actual wind flow is complex near the windbreak [8] [9] [10] [11], but EN1991-1-4 [12] can be used for design purposes; this standard includes a simplified calculation methodology for freestanding walls. The wind action is calculated as

$$
w_{e}=q_{r e f} \cdot c_{p, n e t}
$$

where $q_{r e f}$ is the peak velocity pressure and $c_{p, n e t}$ is the net pressure coefficient. The latter is given as a function of the solidity factor $\varphi$, which is the percentage porosity of the panel in the different wind load zones, named in EN1991-1-4 [12] as A, B, C, and D. As the naming of wind load zones can start from both ends of a 50-m structure, which affects loading on columns, two different load cases were defined regarding wind action in the longitudinal direction. The factor $\varphi$ takes values between 1 (a solid panel) and 0.8 (a panel with 20\% porosity). For values lower than 0.8 (Figure 3), the wind action is calculated in terms of structural elements (see Section 7.7 of EN1991-1-4 [12]). The results are very similar to those presented in [13] [14] [15] [16].

In reality, wind action is not applied only to two perpendicular directions 


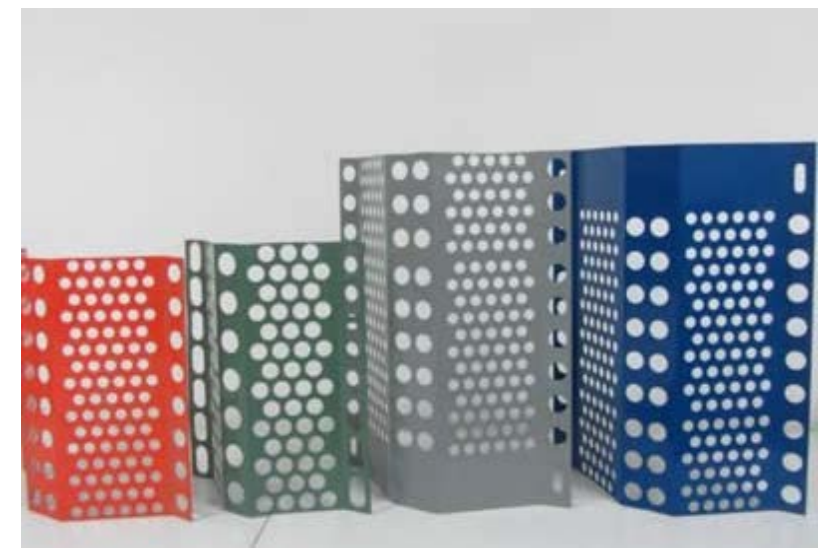

Figure 3. Typical porous metal panels.

separately. Therefore, a percentage of the mean longitudinal action on columns should be applied in the transverse direction. This is accounted for by the friction coefficient described in EN1991-1-4 [12]. The wind action due to friction must be considered for the areas on both sides of the windbreak. The friction coefficient depends on the material surface and takes values between 0.01 and 0.04 . For this study, a conservative value of 0.04 was chosen, representing a very rough surface. The average longitudinal wind action is approximately $12 \mathrm{kN} / \mathrm{m}$ and the reference area of the individual surface of each column (used for the calculation of external forces) is half the area of the external surface parallel to the wind direction for the calculation of friction forces. Therefore, the wind action applied on each column in the transverse direction is $2 \times 0.04 \times 12 \mathrm{kN} / \mathrm{m}=$ $0.96 \mathrm{kN} / \mathrm{m}$.

\section{Case Study}

An electricity producer in Greece requested the design of a windbreak system for improving the performance of their cooling system. The windbreak system had to be $10 \mathrm{~m}$ tall with $0 \%$ porosity. A tall steel structure was required to support the panels, and the windbreak system had to be no farther than $1.0 \mathrm{~m}$ from the existing cooling structure and with columns at intervals of approximately $7 \mathrm{~m}$ (Figure 4).

To reduce the dimensions of the foundation and steel structure, it was decided to support the windbreak structure laterally using cables. To reduce the span to a reasonable length, two cables were used on each side of the steel columns (Figure 5(a)). Furthermore, the base of each column was designed as a hinge so that only vertical loads are transferred to the foundation, namely the self-weight of the structure and the vertical component of the cables. Additionally, because lateral resistance in the longitudinal and transverse directions is provided through the cables and the bracing system, respectively, there was no need for fixed connections at the base of each column. Pinned supports were used to connect the cables to the columns and foundations; this is because cables cannot 


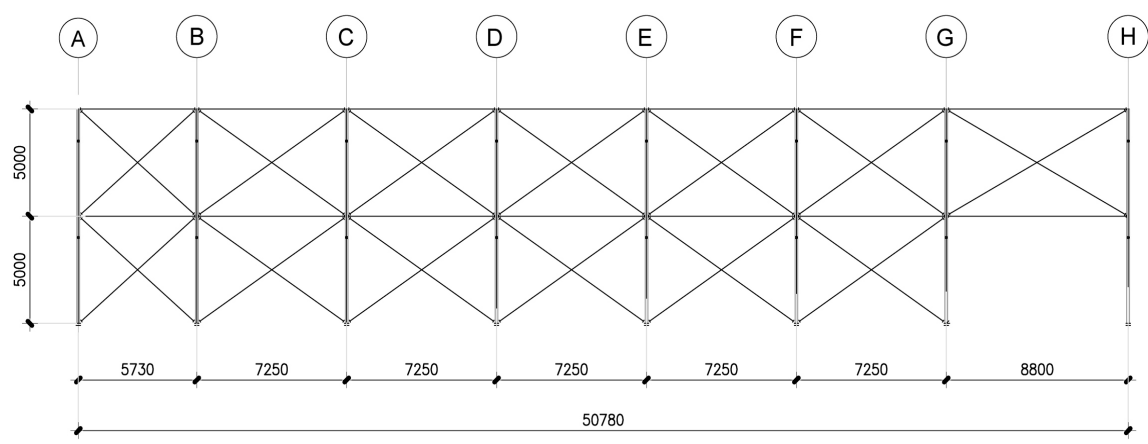

Figure 4. Member arrangement in transverse direction.

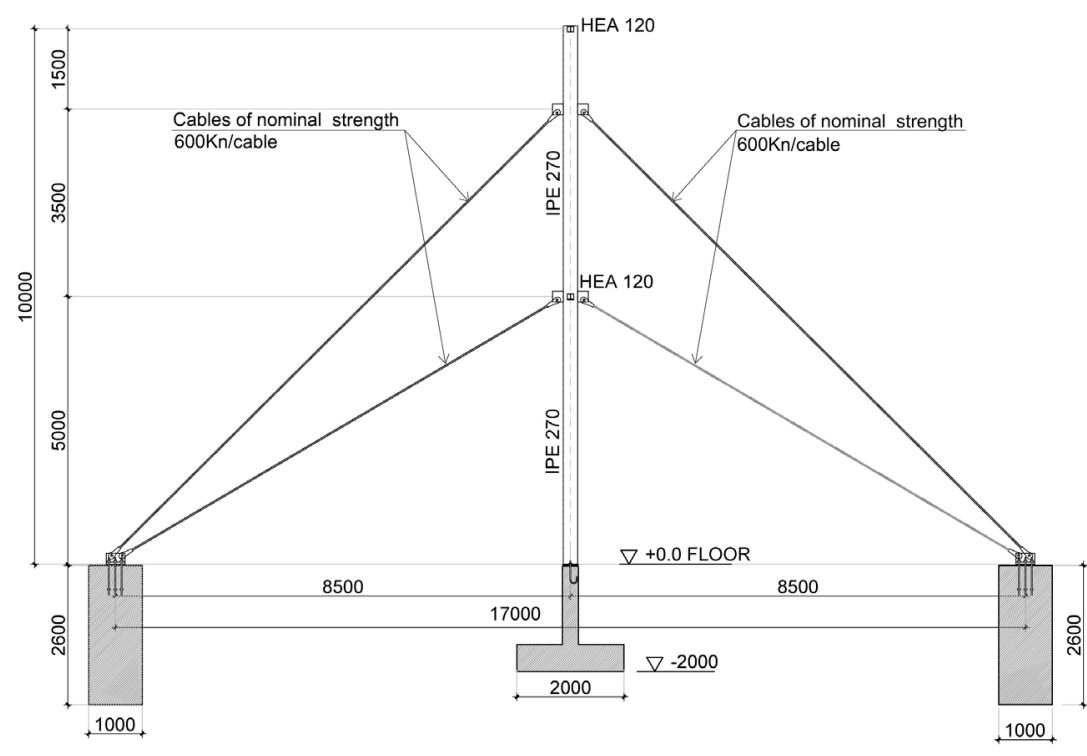

(a)

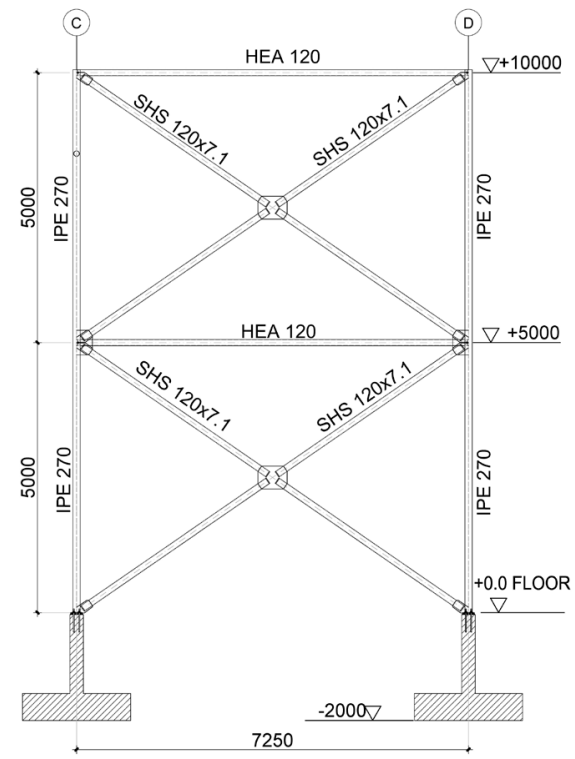

(b)

Figure 5. (a) Column lateral support and cable anchorage in longitudinal direction; (b) Typical bracing system in transverse direction (values in $\mathrm{mm}$ ).

transfer bending moments to their connections. In the transverse direction, in which wind load due to friction applies, steel bracings were used (Figure 5(b)). Two bracings were used to halve the buckling length of the steel columns about the weak axis. A shorter version of a similar system was tested in [17].

Although the wind speed was $33 \mathrm{~m} / \mathrm{s}$ (the higher design wind speed according EN1991-1-4), the required steel column was IPE 270 (S235) with a footing of 1 $\mathrm{m}^{2}$ (Figure 5(b)). The cables were anchored to a reinforced concrete block of dimensions $1 \mathrm{~m} \times 1 \mathrm{~m} \times 2.6 \mathrm{~m}$, which was designed in consideration of the passive pressure from the soil and the friction between the concrete and the soil (Figure 5(a)).

The steel and cable structures were designed according to EN1993-1-1 [18] and EN1993-1-11 [19], respectively, under wind action as per EN1991-4 [12]. The joints were designed according to EN1993-1-8 [20], and the equivalent structural system is shown in Figure 5. Regarding the beams and bracings, 
HEA120 (S235) and SHS $120 \times 7.1$ (S235) were used, respectively. The cables had a diameter of $32 \mathrm{~mm}$, Young's modulus $E=160 \mathrm{GPa}$, yield strength $f_{\mathrm{y}}=$ $1300 \mathrm{MPa}$, and a break load of $600 \mathrm{kN}$.

\section{Design Issues and Optimisation}

As mentioned above, it was assumed that the wind action in the main wind direction applied a uniform pressure to different zones. In other words, the wind pressure applies a uniformly distributed load to the steel columns. These columns were supported laterally by two pairs of cables and were hinged at their bases. A schematic of the resulting bending moments is shown in Figure 6(a). The axial force that develops in a column is mainly due to the vertical component of the load of the cables on the column and the self-weight of the structure. Because the column design considers both the bending moment and the axial force, in terms of ultimate-state design, the developed bending moments should be arranged as M1 > M2 > M3 > M4 (because the axial load in a column decreases from bottom to top). Furthermore, the cable angles ( $\varphi 1$ and $\varphi 2$ in Figure 6(b)) must be as small as possible. This is to reduce the applied axial force and for the cables to restrain the columns laterally without being too thick or strong. However, such a configuration leads to longer cables, and thus higher construction costs. To reduce the lateral torsional (LT) buckling effect, the LT buckling length should be optimised according to the location of large moments.

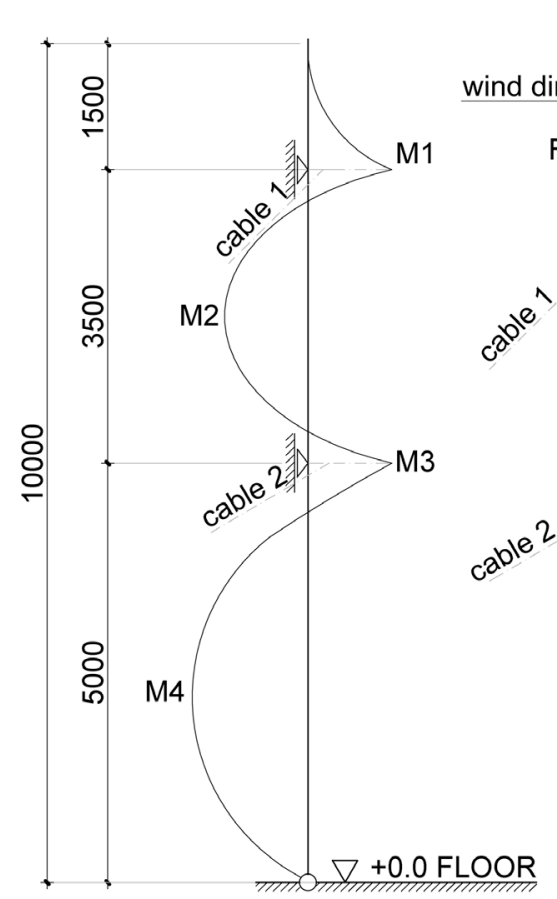

(a)

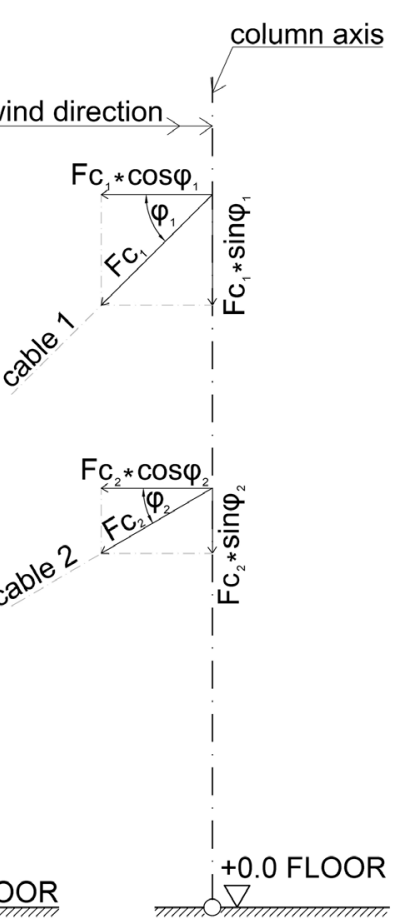

(b)

Figure 6. (a) Schematic of developed bending moments due to wind action in windbreak direction; (b) Actions transferred from cables to steel column (values in $\mathrm{mm}$ ). 
However, the cables account for the majority of the construction cost. Because very long cables are expensive, designing the structure according to EN1993-1-11 [19] increases the total construction cost. Furthermore, the cable anchorage is also expensive. Consequently, to optimise the structure, both cables were anchored at the same footing and were made as short as possible. Moment $\mathrm{M}_{4}$ remained the most unfavourable, in combination with the large axial force resulting from the cable angles. The column cross-section was governed by the $\mathrm{M}_{4}+\mathrm{N}$ code check and designed for a high utilisation ratio $(\sim 0.90)$; this was because the wind speed is known to be lower near the ground because of friction and because the load model of the code is very conservative. Specifically, IPE 270 was stiffened with two plates of dimensions $1000 \times 249.6 \times 10(\mathrm{~mm})$ that were welded between the column flanges, as shown in Figure 7 and Figure 8(a). The same plates were used to improve the torsional stiffness of the columns. These plates were placed in each of the main columns and extended by $0.5 \mathrm{~m}$ on either side from where the bottom cable connected to the column.

One of the main limitations of the contract was the need for an opening between the bottom halves of columns $\mathrm{G}$ and $\mathrm{H}$ (Figure 4) to accommodate a road. This also restricted the length of the cables extending towards the road. Therefore, it was decided to anchor the aforementioned cables to a cantilever column, as shown in Figure 7, for which the HEB360 (S235) cross-section was used. Because there was no bracing system in this location, no lateral restraint was provided to the bottom parts of the columns. Consequently, the columns on either side of the opening were strengthened with a $110-\mathrm{mm}$ piece of IPE 360 (S235), as shown in Figure 8(b).

Another major limitation of the contract was the existence of a tank adjacent to column B (Figure 4). This required the use of two (instead of one) pairs of

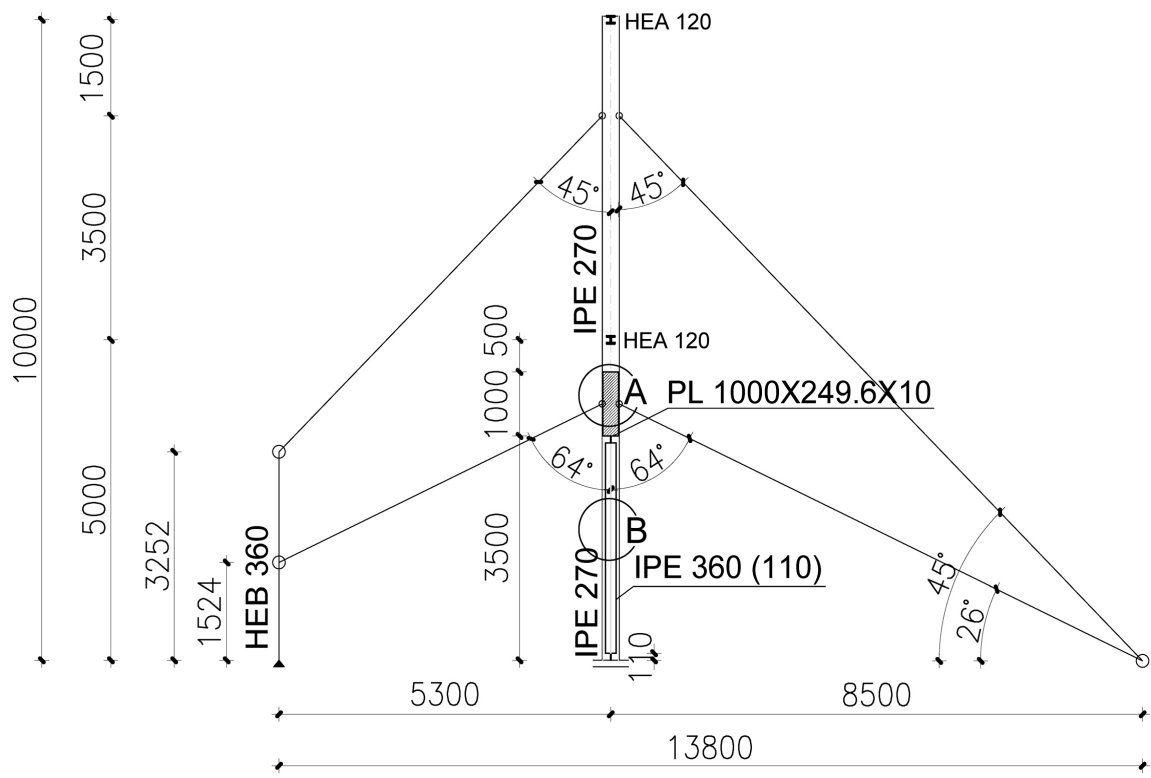

Figure 7. Lateral support at column $\mathrm{G}$ (values in $\mathrm{mm}$ ). 

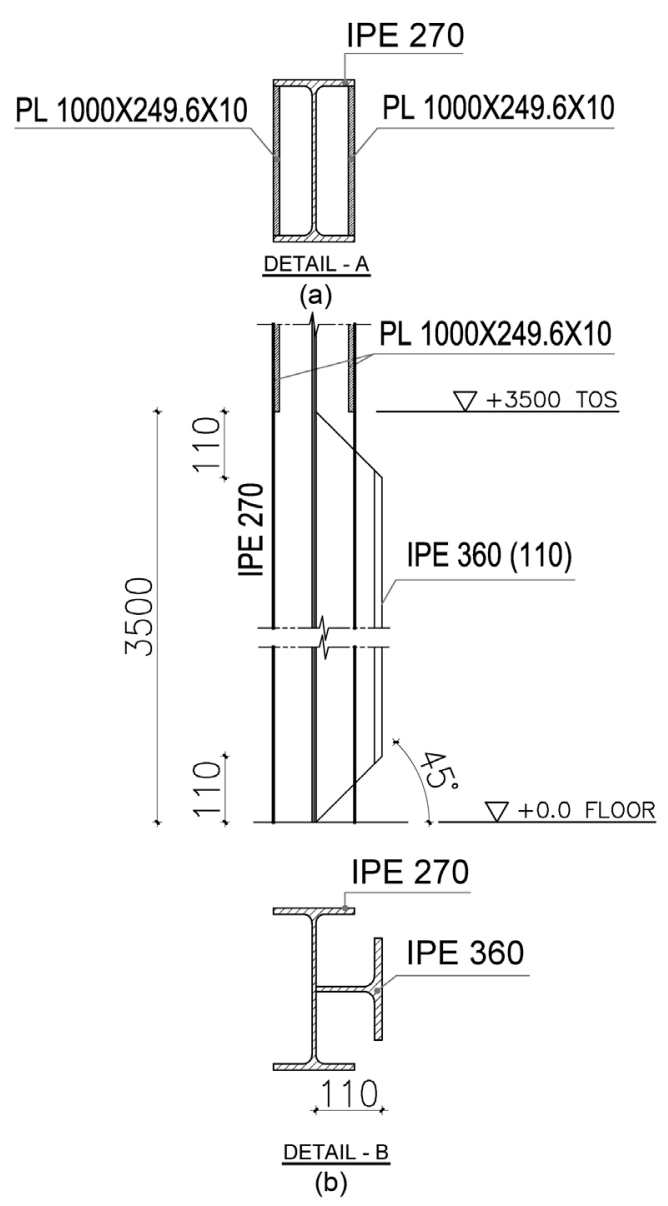

Figure 8. (a) Detail for all columns; (b) Detail for columns $\mathrm{G}$ and $\mathrm{H}$ (values in $\mathrm{mm}$ ).

cables on the respective side of column $\mathrm{B}$, which were anchored to the footings of columns A and C (as shown in Figure 9).

Regarding the pre-tensioning of the cables, some iterations were required to define the optimum pre-tensioning force. Pre-tensioningal ways stiffens cable systems, so the objective of the iterative design was to calculate apre-tensioning force that was sufficiently low to be achieved inexpensively, but sufficiently high for the supports shown in Figure 6(a) to be effective. The lower threshold of this force is particularly important because an initial cable pre-tension that is too low is ineffective for reducing the moments acting on the columns. Combined with the high axial forces induced by the cables, this would violate the member checks according to EN1993-1-1 [18]. For this case study, a pre-tensioning force of 20 $\mathrm{kN}$ was selected at the end of each cable. This force is provided through cable tensioners that are placed between the ends of the cables and the reinforced concrete blocks.

\section{Model in SAP2000 and Results}

The proposed structure was analysed using beam elements in the SAP2000 


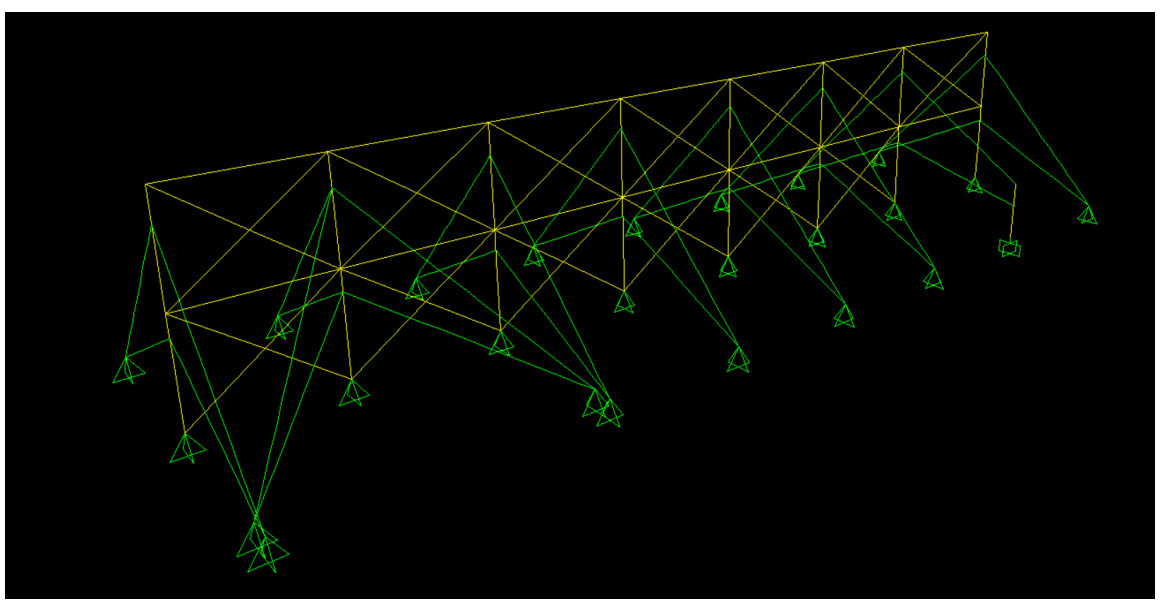

Figure 9. SAP2000 model.

software package. The integrated "Section Designer" utility was used for the stiffened cross-sections shown in Figure 8. The steel design was constructed according to EN1993-1-1 [18], whereas the only criterion for checking the cable design was the tensional axial force. The model used in SAP2000 is shown in Figure 9.

The loads applied on columns in the longitudinal direction for both wind scenarios of wind load zones are presented in Table 1; the loads applied on columns in the transverse direction are equal to $0.96 \mathrm{kN} / \mathrm{m}$, as described above.

Two load cases are examined. Load case 1 includes the transverse wind loading and WIND_Y1 (Figure 10) and load case 2 consists of the transverse wind loading and WIND_Y2 (Figure 11).

As expected for a wind load applied in the longitudinal direction, only the windward cables were placed under tension; the leeward cables were subjected to compression and thus slackened (Figure 12(a)). In contrast, all cables were placed under tension when a wind load was applied in the transverse direction as well (Figure 12(b)). This is very valuable information, as it implies that, during construction, a system comprising a single column and its cables in place can stand without a bracing system, because the cables provide lateral resistance in both directions. Regarding the cable loads, a maximum tension of around 140 $\mathrm{kN}$ was recorded, which is acceptable.

The deformed shape of the structure is shown in Figure 13 for wind loading in the transverse and longitudinal directions, for which maximum displacements of $0.011 \mathrm{~m}$ and $0.024 \mathrm{~m}$, respectively, were recorded. Both displacements comply with the provisions of EN1993-1-1 [18]. Finally, the capacity check performed by SAP2000 according to Eurocode 3 [18] is presented in Figure 14. A maximum value of 0.75 due to axial load-bending moment interaction is recorded.

The results for the supports from SAP2000 (Figure 15) were then imported to Autodesk Structural Robot 2014 to calculate the steel connections. The base connection of the main columns is shown in Figure 16(a). For the cantilever columns, the high bending moment combined with the high uplift and shear 
Table 1. Loads applied on columns in the longitudinal direction for both naming scenarios of the wind load zones.

\begin{tabular}{ccc}
\hline Column & WIND_Y1 $(\mathrm{kN} / \mathrm{m})$ & WIND_Y2 $(\mathrm{kN} / \mathrm{m})$ \\
\hline 1 & 3.72 & 10.54 \\
2 & 10.97 & 13.55 \\
3 & 11.41 & 14.09 \\
4 & 11.41 & 14.09 \\
5 & 14.09 & 11.41 \\
6 & 14.09 & 11.41 \\
7 & 15.59 & 12.62 \\
8 & 13.84 & 4.89 \\
\hline
\end{tabular}

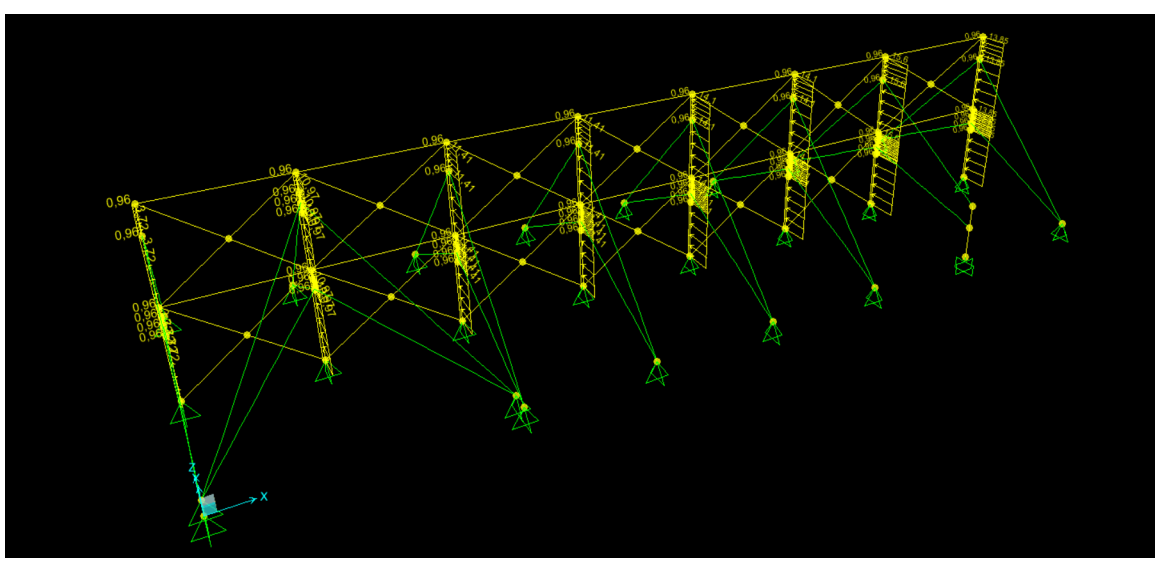

Figure 10. Wind actions on columns for load case 1 (values in $\mathrm{kN} / \mathrm{m}$ ).

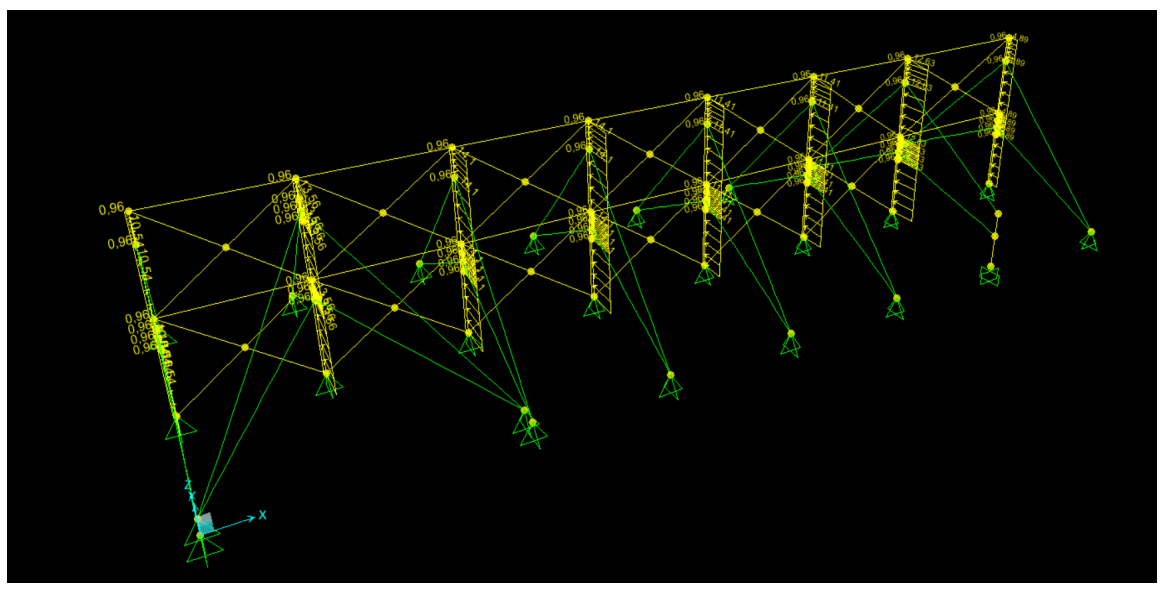

Figure 11. Wind actions on columns for load case 2 (values in $\mathrm{kN} / \mathrm{m}$ ).

forces required the stiffened fixed connection shown in Figure 16(b).

Regarding the cable connections of the other structural members, Figure 17(b) shows the gusset plates used to transfer wind loads from the columns to the cables, and Figure 17(a) shows the connection used to transfer the cable loads to the ground. 


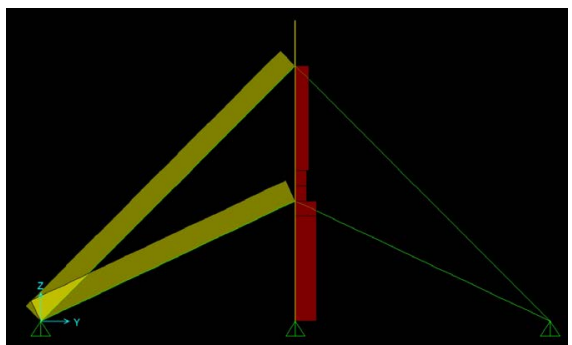

(a)

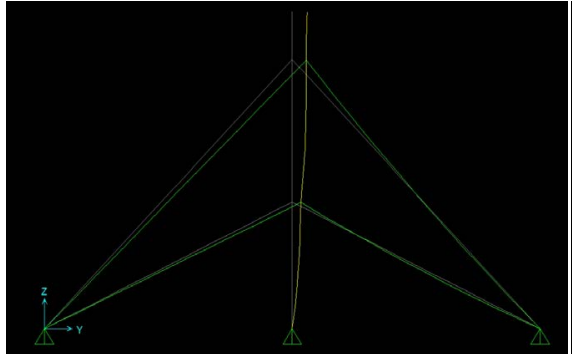

(c)

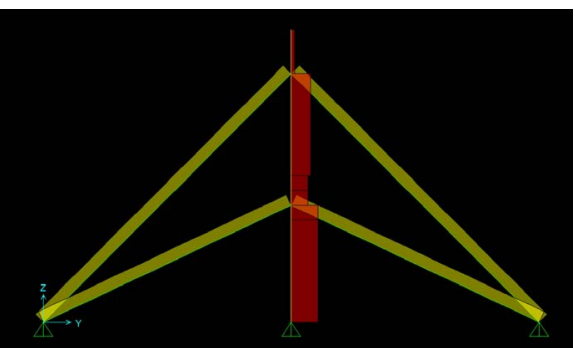

(b)

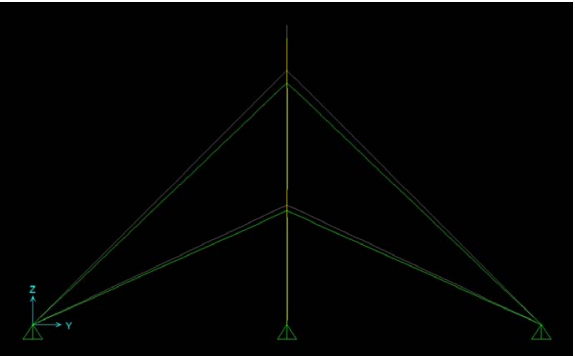

(d)

Figure 12. Deformed structure and axial diagram for wind loading in (a) longitudinal direction and (b) transverse direction.

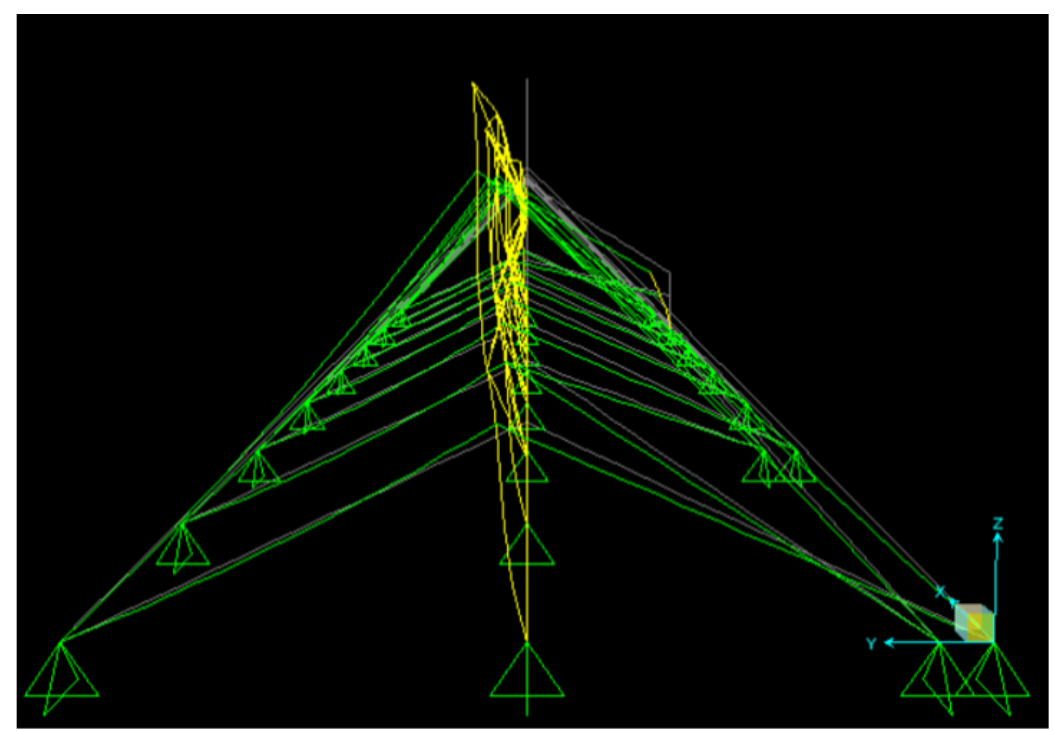

(a)

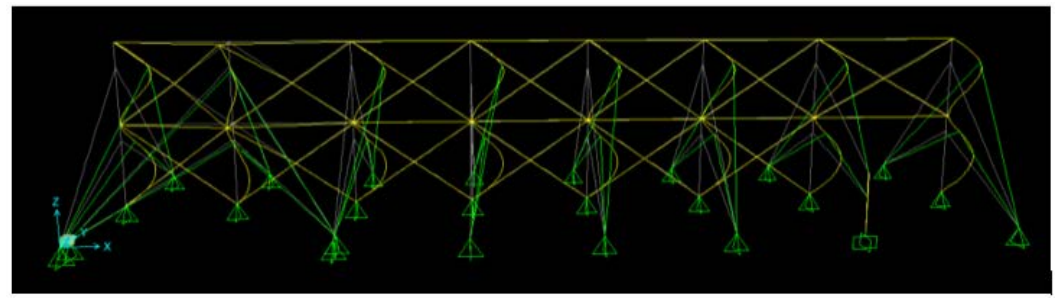

(b)

Figure 13. Deformed shape for wind loading in (a) longitudinal direction and (b) transverse direction. In both images, the deflections are scaled by a factor of 100 , with the grey outline representing the undeformed shape. 


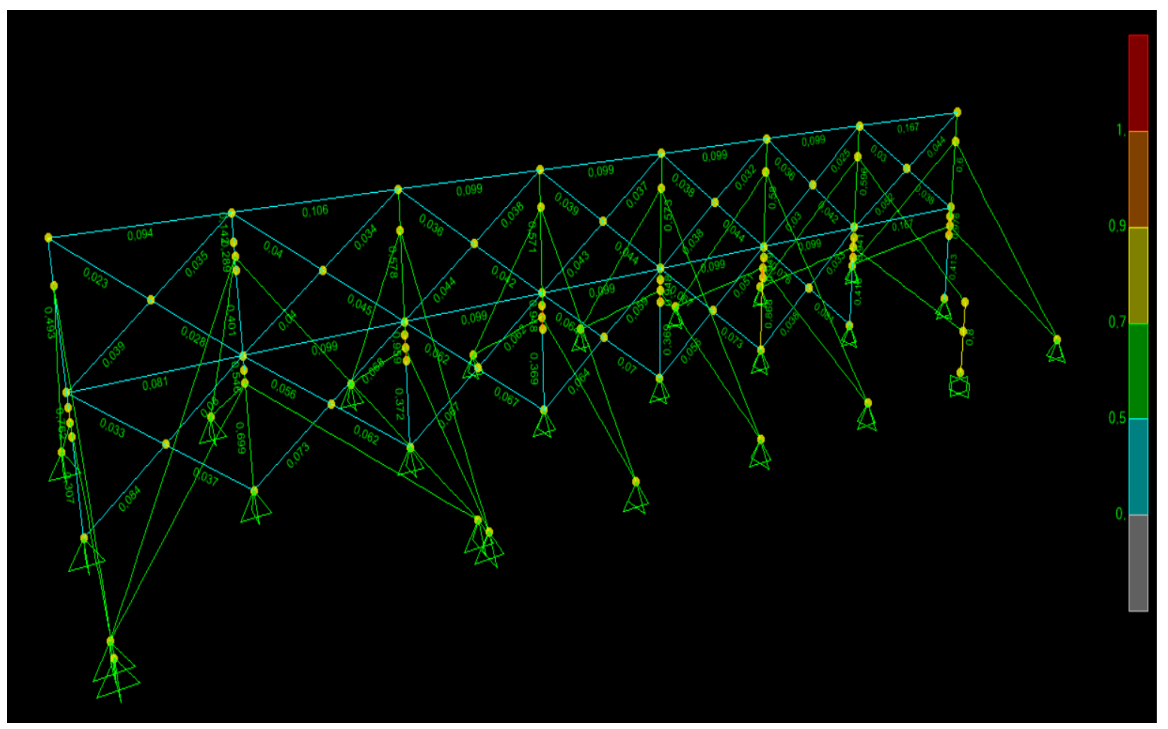

Figure 14. P-M ratio colours and values. All members passed.

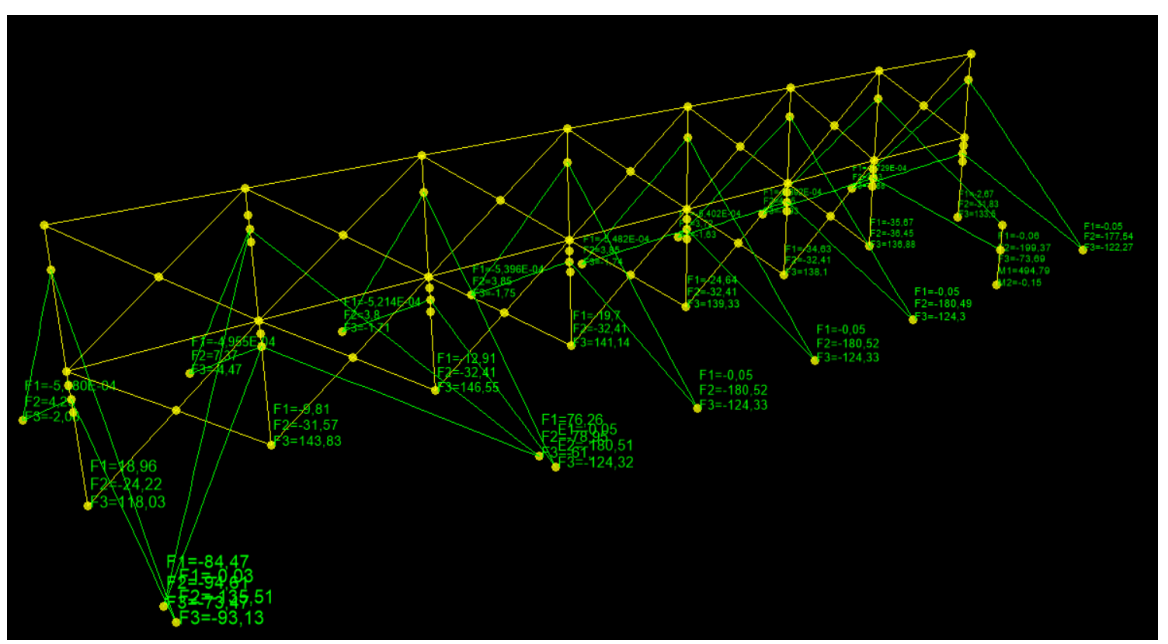

Figure 15. Support reactions (values in $\mathrm{kN}$ and $\mathrm{kNm}$ ).

\section{Alternative Design Proposal: Cantilevered Columns}

The key difference in this alternative solution is that a huge bending moment is expected at the base of the column. The loads applied on the columns in each direction are the same as in the case of the cable-stayed solution. These loads are shown in Figure 18 and Figure 19 for load cases 1 and 2, respectively.

As expected, a bending moment of about $700 \mathrm{kN} \cdot \mathrm{m}$ developed at the base of each cantilever, as shown in Figure 20. Furthermore, the effective length for buckling about the strong axis is $20 \mathrm{~m}$, whereas the effective length for LT buckling is assumed to be somewhere in the range $10-20 \mathrm{~m}$. To determine this value more accurately, further investigation would be necessary regarding the restraint provided to columns by the beams and the bracings.

For the design checks of Eurocode 3 to be satisfied, HEA700 cross-sections were required for the columns, which are about 5.6 times heavier than the 


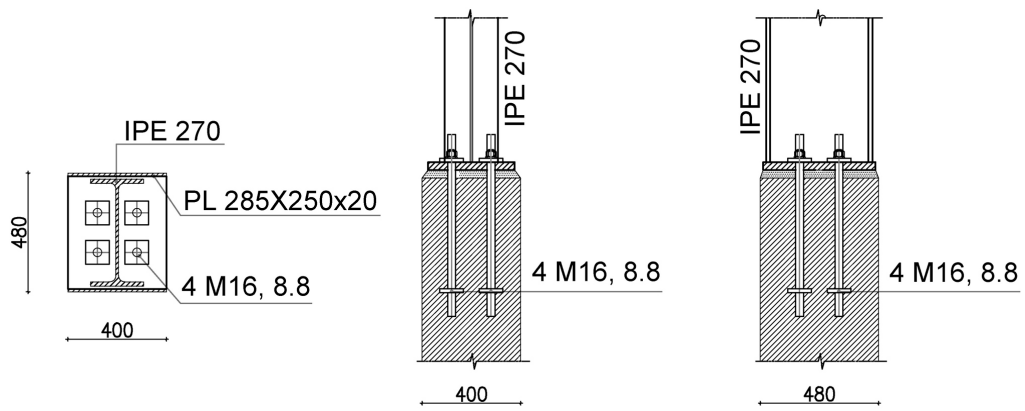

(a)
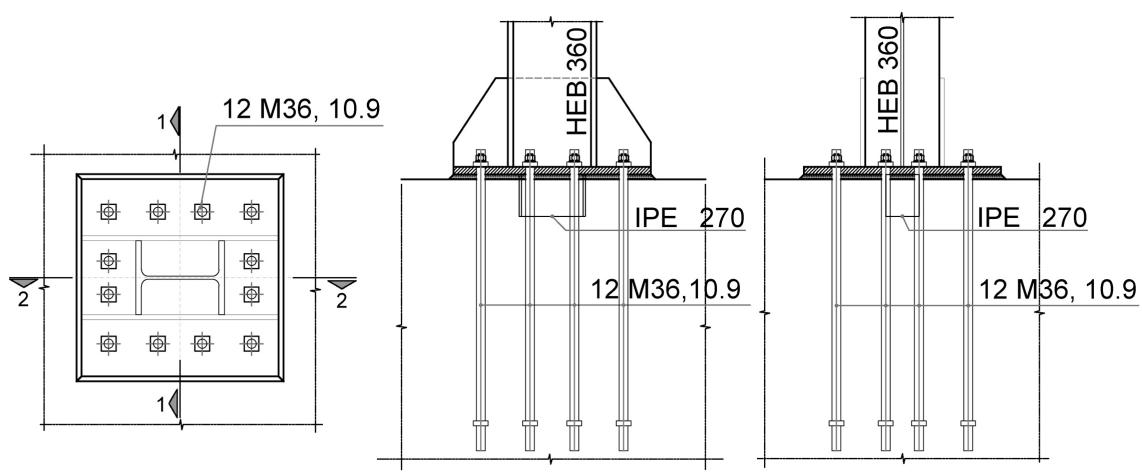

(b)

Figure 16. Base connection of (a) main columns and (b) cantilever columns (values in $\mathrm{mm})$.

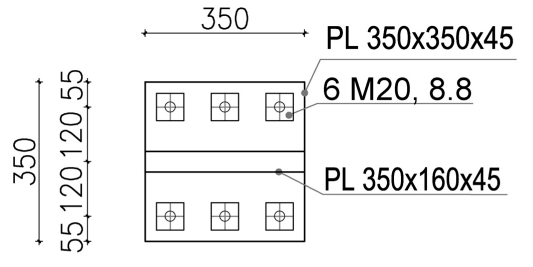

$5,5,120,120,55$

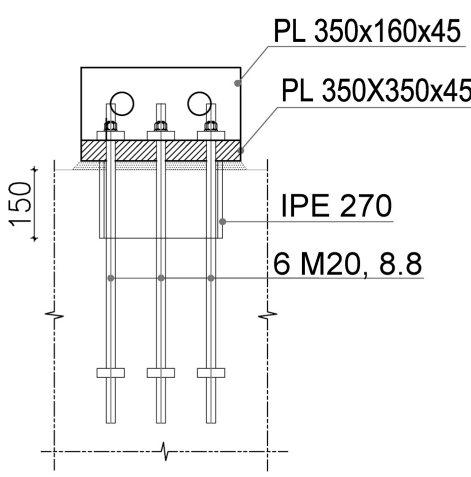

(a)

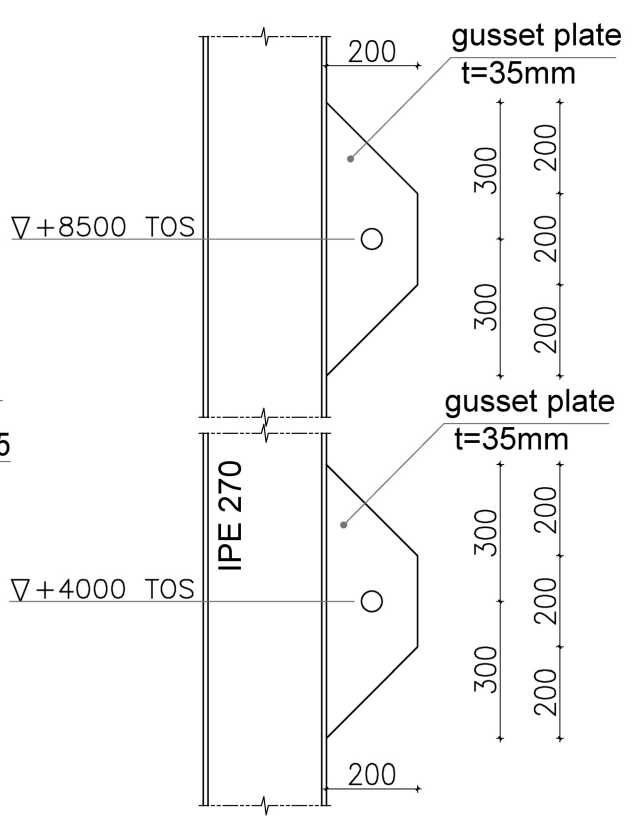

(b)

Figure 17. Cable connection to (a) concrete block and (b) column (values in $\mathrm{mm}$ ).

IPE270 used in the cable-stayed solution. The capacity check performed by SAP2000 according to Eurocode 3 [18] is presented in Figure 21. A maximum 


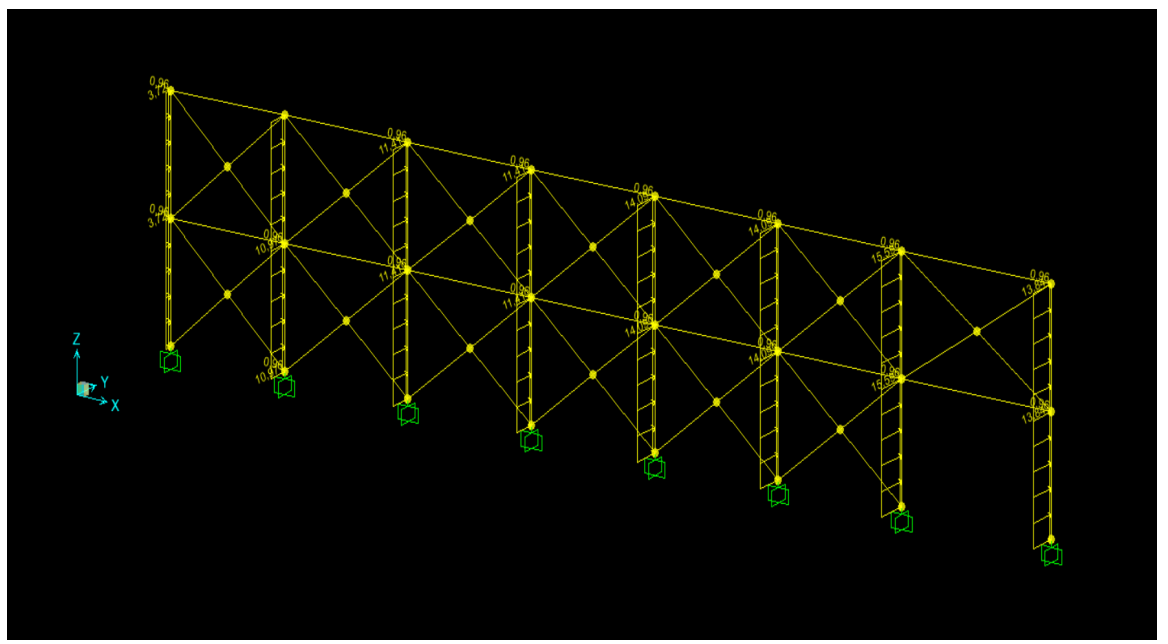

Figure 18. Wind loads on cantilevered columns for load case 1 (values in $\mathrm{kN} / \mathrm{m}$ ).

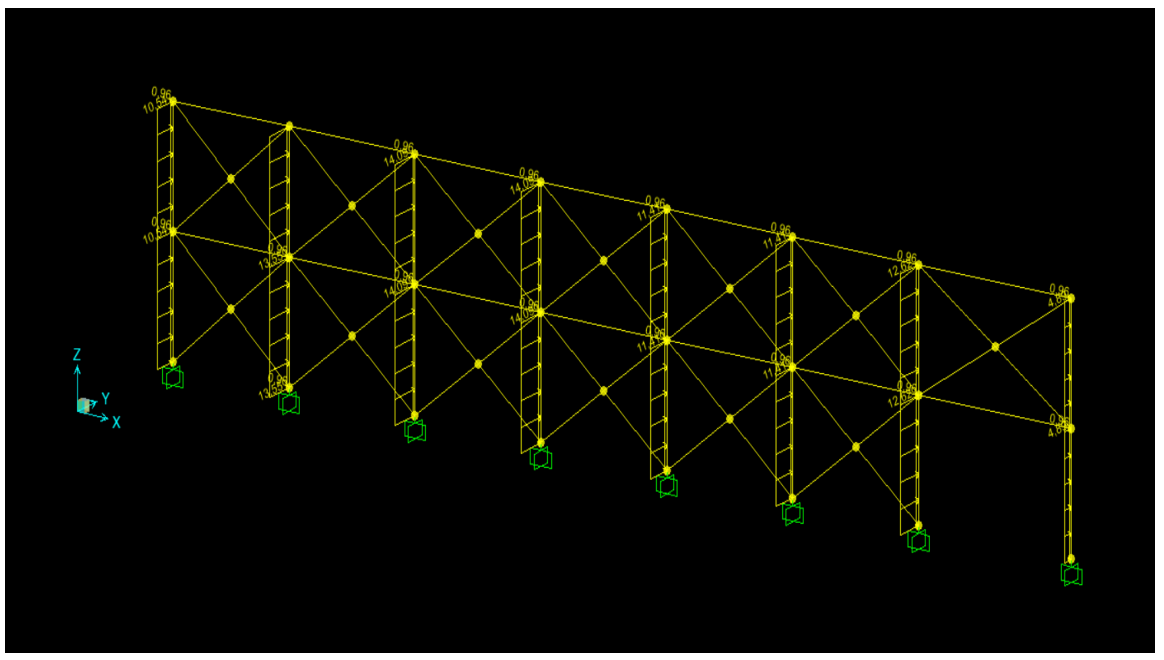

Figure 19. Wind loads on cantilevered columns for load case 2 (values in $\mathrm{kN} / \mathrm{m}$ ).

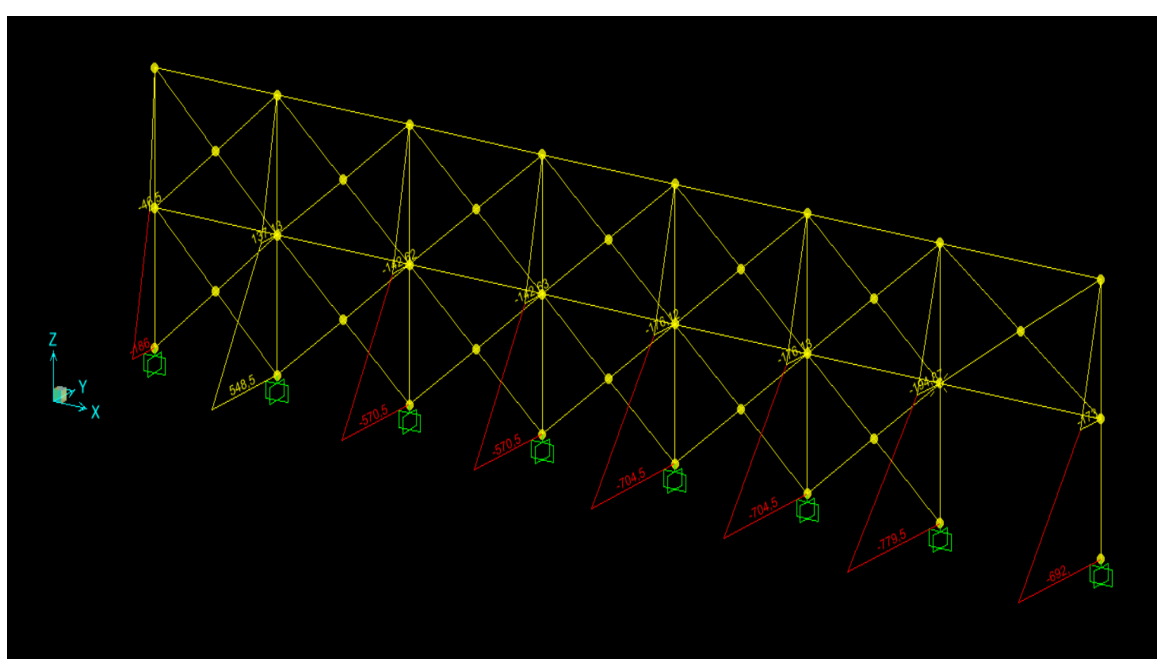

Figure 20. Base connection of (a) main columns and (b) cantilever columns (values in $\mathrm{kN} \cdot \mathrm{m}$ ). 


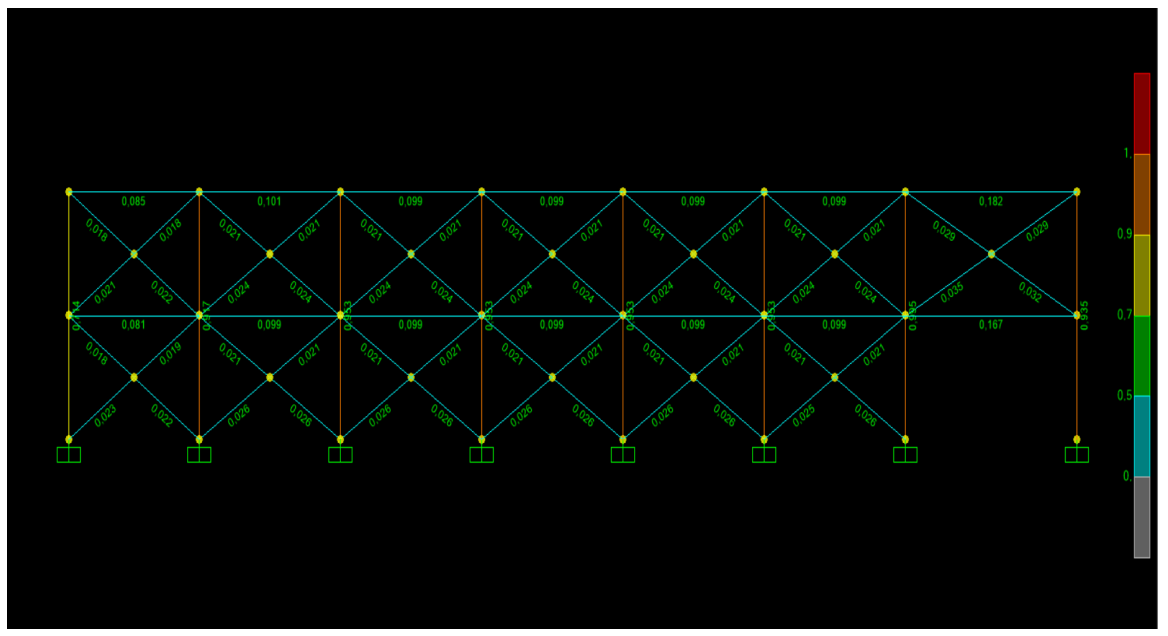

Figure 21. P-M ratio colours and values. All members passed.

Table 2. Cost comparison between the cable-stayed and cantilevered solutions.

\begin{tabular}{ccc}
\hline & Cable-stayed solution & Cantilevered solution \\
\hline Cost of steel columns & $25,000 €$ & $95,000 €$ \\
Cost of foundation (for cables) & $15,000 €$ & - \\
Cost of foundation (for columns) & $15,000 €$ & $100,000 €$ \\
Cost of cables & $13,000 €$ & - \\
SUM & $\mathbf{8 8 , 0 0 0 €}$ & $\mathbf{1 9 5 , 0 0 0 €}$ \\
\hline
\end{tabular}

value of 0.95 due to axial load-bending moment interaction is recorded.

Another consequence of the fixed-base columns is the need for much larger foundations. More specifically, the foundations required to withstand the huge bending moment combined with the related shear force and axial load would cost about three times more than those in the cable-stayed design.

\section{Cost Comparison between Two Solutions}

A cost comparison was made on the basis of the three parameters that differ between the cable-stayed and the cantilevered solution, as the rest of the construction works should cost about the same in both solutions. These parameters include the cost of the steel columns, the cost of the foundations, and the cost of the cables. The results of this comparison are presented in Table 2.

As can be seen from Table 2, the cantilevered solution would cost approximately $87,000 €$ more.

\section{Conclusion}

This paper has presented basic design information for a tall windbreak structure. The proposed structure was supported with cables in the main wind direction to produce an economical solution, with the steel columns supported by bracings in their weaker direction. The windbreak constructed had a length of roughly 85 
$\mathrm{m}$, and the total construction cost was $88,000 €$. This cost would be approximately $50 \%$ higher if the design solution did not use cables, and instead had the columns acting as cantilevers. Another important merit of the proposed method is that the design is much safer than the alternative cantilever solution, which could collapse if a plastic hinge formed at the base. The cable-supported structure, however, is able to redistribute excessive applied loads.

\section{Conflicts of Interest}

The author declares no conflicts of interest regarding the publication of this paper.

\section{References}

[1] Moskovaya, I.V., Olishevskiy, A.T. and Lazareva, L.P. (2017) Assessment of Efficiency of Windbreak and Dust Suppression Walls for Coal Terminals. IOP Conference Series: Earth and Environmental Science, 87, Article ID: 042010. https://doi.org/10.1088/1755-1315/87/4/042010

[2] Řeháček, D., Khel, T., Kučera, J., Vopravil, J. and Petera, M. (2017) Effect of Windbreaks on Wind Speed Reduction and Soil Protection against Wind Erosion. Soil \& Water Research, 12, 128-135. https://doi.org/10.17221/45/2016-SWR

[3] Barbosa, C., Severino, C., Matsumoto, E., Guijun, L., Labaki, L., Leone, M., Barbosa, P., Vatavu, P., Camargo, R. and Forti, T. (2017) Windbreaks Working as Barriers to High Speed Winds for Protection of Electric Power Transmission Lines and Towers. Engineering Failure Analysis, 82, 753-764. https://doi.org/10.1016/j.engfailanal.2017.06.042

[4] Jian, Z., Bo, L. and Mingyue, W. (2018) Study on Windbreak Performance of Tree Canopy by Numerical Simulation Method. Journal of Computational Multiphase Flows, 10, 259-265. https://doi.org/10.1177/1757482X18791901

[5] Kemper, F.H. and Feldman, M. (2018) Wind Load Assumptions for Permeable Cladding Elements Considering the Installation Context. Journal of Wind Engineering \& Industrial Aerodynamics, 184, 277-288.

https://doi.org/10.1016/j.jweia.2018.10.011

[6] Li, N., Yang, Z., Zhang, Q., Feng, R. and Wu, Y. (2018) Numerical Study on Windbreaks with Different Porosity in Photovoltaic Power Plants. Energy Procedia, 158, 577-582.

[7] Mohebbi, M. and Resvani, A.M. (2019) Analysis of the Effects of Lateral Wind on a High Speed Train on a Double Routed Railway Track with Porous Shelters. Journal of Wind Engineering \& Industrial Aerodynamics, 184, 116-127. https://doi.org/10.1016/j.jweia.2018.11.011

[8] Gu, H., Zhe, Z., Wang, H. and Qi, C. (2015) A Numerical Study on the Effect of Roof Windbreak Structures in an Air-Cooled System. Applied Thermal Engineering, 90, 684-693. https://doi.org/10.1016/j.applthermaleng.2015.07.030

[9] Liu, B., Qu, J., Zhang, W., Tan, L. and Gao, Y. (2014) Numerical Evaluation of the Scale Problem on the Wind Flow of a Windbreak. Scientific Reports, 4, Article No. 6619. https://doi.org/10.1038/srep06619

[10] Hong, S.W., Lee, I.B. and Seo, I.H. (2015) Modelling and Predicting Wind Velocity Patterns for Wind Break Fence Design. Journal of Wind Engineering and Industrial 
Aerodynamics, 142, 53-64. https://doi.org/10.1016/j.jweia.2015.03.007

[11] Wang, W., Liu, P., Li, Z., Ni, W., Liu, J. and Li, Y. (2015) A Numerical Study on the Improving Techniques of the Cooling Performance of a Natural Draft Dry Cooling Tower under Crosswind. Chemical Engineering Transactions, 45, 1081-1086.

[12] EN1991-1-4 (2005) Eurocode 1: Actions on Structures-Part 1-4: General Actions-Wind Actions. European Committee for Standardization, Brussels.

[13] Giannoulis, A., Mistriotis, A. and Briassoulis, D. (2010) Experimental and Numerical Investigation of the Air Flow around a Raised Permeable Panel. Journal of Wind Engineering and Industrial Aerodynamics, 98, 808-817. https://doi.org/10.1016/j.jweia.2010.07.005

[14] Giannoulis, A., Stathopoulos, T., Briassoulis, D. and Mistriotis, A. (2012) Wind Loading on Vertical Panels with Different Permeabilities. Journal of Wind Engineering and Industrial Aerodynamics, 107-108, 1-16. https://doi.org/10.1016/j.jweia.2012.02.014

[15] Allori, D., Bartoli, G. and Mannini, C. (2013) Wind Tunnel Tests on Macro-Porous Structural Elements: A Scaling Procedure. Journal of Wind Engineering and Industrial Aerodynamics, 123, 291-299. https://doi.org/10.1016/j.jweia.2013.09.011

[16] Briassoulis, D., Mistriotis, A. and Giannoulis, A. (2010) Wind Forces on Porous Elevated Panels. Journal of Wind Engineering and Industrial Aerodynamics, 98, 919-928. https://doi.org/10.1016/j.jweia.2010.09.006

[17] Giannoulis, A., Mistriotis, A. and Briassoulis, D. (2015) Design and Analysis of the Response of Elastically Supported Wind-Break Panels of Two Different Permeabilities under Wind Load. Biosystems Engineering, 129, 57-69. https://doi.org/10.1016/j.biosystemseng.2014.09.013

[18] EN1993-1-1 (2005) Eurocode 3: Design of Steel Structures-Part 1-1: General Rules and Rules for Buildings. European Committee for Standardization, Brussels.

[19] EN1993-1-11 (2006) Eurocode 3-Design of Steel Structures-Part 1-11: Design of Structures with Tension Components. European Committee for Standardization, Brussels.

[20] EN1993-1-8 (2005) Eurocode 3: Design of Steel Structures-Part 1-8: Design of Joints. European Committee for Standardization, Brussels. 